\title{
Contribution of flowering trees to urban atmospheric biogenic volatile organic compound emissions
}

\author{
R. Baghi ${ }^{1,2}$, D. Helmig ${ }^{1}$, A. Guenther ${ }^{3}$, T. Duhl ${ }^{3}$, and R. Daly ${ }^{1}$ \\ ${ }^{1}$ Institute of Arctic and Alpine Research, University of Colorado, Boulder, CO 80309, USA \\ ${ }^{2}$ Laboratoire d'Aérologie, Université de Toulouse, France \\ ${ }^{3}$ National Center for Atmospheric Research, Boulder, CO 80307, USA
}

Correspondence to: D. Helmig (detlev.helmig@ colorado.edu)

Received: 13 January 2012 - Published in Biogeosciences Discuss.: 15 March 2012

Revised: 4 July 2012 - Accepted: 13 September 2012 - Published: 5 October 2012

\begin{abstract}
Emissions of biogenic volatile organic compounds (BVOC) from urban trees during and after blooming were measured during spring and early summer 2009 in Boulder, Colorado. Air samples were collected onto solid adsorbent cartridges from branch enclosures on the tree species crabapple (Malus sp.), horse chestnut (Aesculus carnea, "Ft. McNair"), honey locust (Gleditsia triacanthos, "Sunburst"), and hawthorn (Crataegus laevigata, "Pauls Scarlet"). These species constitute $\sim 65 \%$ of the insect-pollinated fraction of the flowering tree canopy (excluding catkin-producing trees) from the street area managed by the City of Boulder. Samples were analyzed for $\mathrm{C}_{10}-\mathrm{C}_{15}$ BVOC by thermal desorption and gas chromatography coupled to a flame ionization detector and a mass spectrometer (GC/FID/MS). Identified emissions and emission rates from these four tree species during the flowering phase were found to vary over a wide range. Monoterpene emissions were identified for honey locust, horse chestnut and hawthorn. Sesquiterpene emissions were observed in horse chestnut and hawthorn samples. Crabapple flowers were found to emit significant amounts of benzyl alcohol and benzaldehyde. Floral BVOC emissions increased with temperature, generally exhibiting exponential temperature dependence. Changes in BVOC speciation during and after the flowering period were observed for every tree studied. Emission rates were significantly higher during the blooming compared to the post-blooming state for crabapple and honey locust. The results were scaled to the dry mass of leaves and flowers contained in the enclosure. Only flower dry mass was accounted for crabapple emission rates as leaves appeared at the end of the flowering period. Total normalized $\left(30^{\circ} \mathrm{C}\right)$ monoterpene emissions from
\end{abstract}

honey locust were higher during flowering $\left(5.3 \mu g \mathrm{~g} \mathrm{~g}^{-1} \mathrm{~h}^{-1}\right)$ than after flowering $\left(1.2 \mu \mathrm{gC} \mathrm{g}^{-1} \mathrm{~h}^{-1}\right)$. The total normalized BVOC emission rate from crabapple $\left(93 \mu \mathrm{gC} \mathrm{g}^{-1} \mathrm{~h}^{-1}\right)$ during the flowering period is of the same order as isoprene emissions from oak trees, which are among the highest BVOC flowering period floral emissions observed from plants to date. These findings illustrate that during the relatively brief springtime flowering period, floral emissions constitute by far the most significant contribution to the BVOC flux from these tree species, some of which are leafless at this time. Experimental results were integrated into the MEGAN biogenic emission model and simulations were performed to estimate the contribution of floral BVOC emissions to the total urban BVOC flux during the spring flowering period. The floral BVOC emitted during this three-month simulation are equivalent to $11 \%$ of the integrated monoterpene flux for the Boulder urban area.

\section{Introduction}

Volatile organic compounds (VOC) play an important role in atmospheric chemistry, in particular in secondary pollutant formation (e.g., tropospheric ozone and secondary organic aerosols) (Andreae and Crutzen, 1997). Biogenic VOC emissions (BVOC) from vegetation comprise $\sim 90 \%$ of global terrestrial non-methane VOC emissions annually (Fuentes et al., 2000). BVOC emissions are highly dependent on vegetation activity and biomass, which are both governed by seasonal changes. BVOC flux estimates used in air quality models rely on emission rates, vegetation characteristics, 
and weather conditions. Seasonal changes are not well understood and are thus difficult to account for. In particular, BVOC emissions from flowers during the blooming period are generally not considered. Ornamental vegetation with colorful and/or fragrant flowers is often planted to brighten up urban areas. This general vegetation group contributes to VOC concentrations to an extent that could potentially impact air quality. To our knowledge only three studies in the literature have addressed the possibility of increased atmospheric VOC during the blooming period (Arey et al., 1991; Ciccioli et al., 1999; Müller et al., 2002). Flower volatiles have been widely studied in botanical research for their role in plant-pollinator and plant-herbivore interactions. Therefore, an abundant body of literature on BVOC emissions from flowers is available. However, most studies on floral BVOC emissions report only qualitative results. A summary of this literature is presented in Table 1 in the Supplement. A few studies report emission rates, but it is difficult to incorporate them into quantitative models. For example, Baraldi et al. (1999) and Rapparini et al. (2001) report emission rates in $\mu \mathrm{g}$ per 100 flowers $\mathrm{h}^{-1}$. Ibrahim et al. (2010) detected significantly higher isoprene and monoterpene emission rates from flower branches compared to vegetative branches of Yeheb tree (Cordeauxiaedulis) and express these findings in $\mu \mathrm{g}$ (g dry weight $)^{-1} \mathrm{~h}^{-1}$. Müller et al. (2002) reported terpene fluxes from flowering rape plants of $16-32 \mu \mathrm{g} \mathrm{m}^{-2}$ (ground area) $\mathrm{h}^{-1}$, and Rodriguez-Sanoa et al. (2011) observed a mean volatile production of $48.6 \mathrm{ng} \mathrm{h}^{-1}$ per flower of blueberry.

The review of this literature demonstrates that there is a significant amount of BVOC emitted by flowers and that there is a high variability in emissions. There seems to be a common pattern in that there are higher VOC emission rates from flowering branches than vegetative branches (Arey et al., 1991; Ibrahim et al., 2010). These issues motivated us to study the floral emissions from urban trees in the City of Boulder and their contribution to the urban BVOC flux to assess the potential effect of flowering tree emissions on urban air quality.

\section{Experimental}

\subsection{Site description}

The field site was located in the CreekSide Tree Nursery in Boulder, Colorado, USA. An enclosed trailer sitting within the tree nursery was used as a mobile field laboratory. Flowering trees were provided by the nursery during the measurement period corresponding to the blooming season. Four tree species were studied: crabapple (Malus sp.), hawthorne (Crataegus laevigata, "Pauls Scarlet"), horse chestnut (Aesculus carnea, "Ft. McNair"), and honey locust (Gleditsia triacanthos, "Sunburst"). Together, honey locust, crabapple and hawthorn represent $\sim 65 \%$ of the insect pollinated, non- catkin-producing flowering tree canopy in the City of Boulder according to a municipal tree resource analysis report from the City of Boulder (City of Boulder, 2005; see Supplement Table 2), while horse chestnut represents less than $1 \%$. Only those flowering species present in the urban tree inventory that produce conspicuous, showy floral structures and are assumed to be insect pollinated were considered for screening. The rationale for this sampling decision was that these tree species would be most likely to invest resources into floral BVOC production for the purpose of pollinator attraction. The remaining $35 \%$ of the insect-pollinated, noncatkin-producing flowering tree species in Boulder is comprised of 9 species, which were not screened during the course of this study, in part because of limitations in the number of branch enclosure experiments that could be operated simultaneously at the time of the study, and also because specimens were not available for screening at the tree nursery during the sampling campaign. All investigated trees were between 2 and $3 \mathrm{~m}$ tall and between 3 and $5 \mathrm{yr}$ old. They were kept in their planting pots during the experiments.

\subsection{Sampling}

Sampling methods and materials used for the BVOC emission measurements followed the procedures recommended in Ortega and Helmig (2008). The studied vegetation was enclosed in a Tedlar bag with minimal contact of foliage and flowers with the bag. The bag was attached at the branch base with a Velcro strap. Ambient air was filtered for particles (respirator filter, Mersorb, Part no. 463532, Mine Safety Appliances Company, Pittsburgh, PA) and scrubbed of ozone (cartridge with $\mathrm{MnO}_{2}$-coated screens, O.B.E. Corp. Fredericks-burg, TX) and pumped at $251 \mathrm{~min}^{-1}$ into the enclosure providing a slight overpressure inside the bag. The turnover time inside the enclosure was estimated as 2.0 to $2.5 \mathrm{~min}$. A cold trap was used to reduce moisture and cool the air pumped into the enclosure. A small flow of a 5-component reference standard mixture, spanning a wide volatility range was doped into the purge air to serve as a reference for tracing compound recovery rates from the experiment (Ortega and Helmig, 2008). The standard was composed of 5 aromatic compounds including toluene, isopropylbenzene, tetrahydronaphthalene, tri-isopropyl-benzene and n-nonyl-benzene, and concentrations were determined using a gas chromatograph calibrated with a multi-componentalkane gas standard as described in Helmig et al. (2003). The aromatic mixture was introduced in the main purge flow at a mass flow-controlled rate of $6.5 \mathrm{ml} \mathrm{min}^{-1}$. The resulting mixing ratio of the five compounds ranged from 2.2 to 11.4 ppbv. Two automated sampling devices (Helmig et al., 2004a) were used for collection of emission samples, allowing for 10 to 20 samples to be collected sequentially. An ozone scrubber composed of a $\mathrm{NaS}_{2} \mathrm{O}_{3}$-coated glass-fiber filter (Helmig et al., 2006) was placed at the auto-sampler inlet. Samples were collected onto glass tubes filled with a 
multi-adsorbent bed composed of half TenaxGR (Buchem BV, Apeldoorn, The Netherlands) and half Carboxen 1016 (Supelco, Bellefonte, PA, USA). A second adsorbent cartridge (breakthrough cartridge) was placed in series with every 10th sample cartridge. Analysis of the breakthrough cartridges was used to ensure that sampled compounds did not make their way through the primary adsorbent cartridge. Sampling flow was $200 \mathrm{ml} \mathrm{min}^{-1}$ for a typical sample volume of 121 .

One tree of each species was selected for this study. For each tree, a single branch was chosen to be sampled repeatedly over the course of the study. The enclosure was installed as carefully as possible to minimize any disturbance effects. Figure 1 shows a picture of the enclosure setup for one of the crabapple experiments. Sampling on a branch enclosure started no sooner than six hours after the enclosure was installed. This delay allowed the plant and the enclosure to reach an equilibrium state, and also allowed for any stressinduced emissions caused by the installation of the enclosure to subside (Tarvainen et al., 2005). Sampling times varied from one hour during daytime to $2 \mathrm{~h}$ during nighttime. Two sets of enclosure equipment were used simultaneously when several trees were blooming at the same time. Approximately 400 samples were collected over the course of this study, from 16 April to 19 June 2009: 99 samples on hawthorn, 40 on crabapple, 145 on chestnut, and 70 samples on honey locust. In addition, 20 samples of the inlet purge air were collected to allow for a comparison of the aromatic reference standard recovery rates from the experiment. For each tree a second set of emission samples was collected once flowers had withered to obtain reference measurements of the foliar BVOC emissions from each species after the flowering period had ended.

Samples collected at the field site were brought back to the laboratory and stored in a freezer for 1 to 2 days before being analysed. Thermal desorption using a Perkin-Elmer ATD 400 allowed the sample to be transferred from the cartridge to a GC (Model 5890, Hewlett-Packard). Separation was achieved on a $0.32 \mathrm{~mm}$ i.d., $50 \mathrm{~m}$ long, $5 \mu \mathrm{m}$ film thickness DB-1 capillary column (Agilent). Analyte identification and quantification were performed using a mass spectrometer (Model 5970, Hewlett-Packard) and flame ionization detector (FID) after splitting the column flow. Similar instrumentation and calibration procedures have been described previously (Helmig et al., 2004b; Ortega et al., 2008). Compound identification was achieved using relative retention times, along with comparing mass spectra with the NIST database and Adams (1989). All quantifications were performed using the FID signals. The typical limit of detection of the system during this study was $50 \mathrm{pptv}$ and the typical accuracy was $\sim 10 \%$. Isoprene (which previously has not been reported as a major floral emission) was not quantified as it was not sufficiently retained under the chosen GC conditions. Quantitative results are reported in mass of carbon (C).

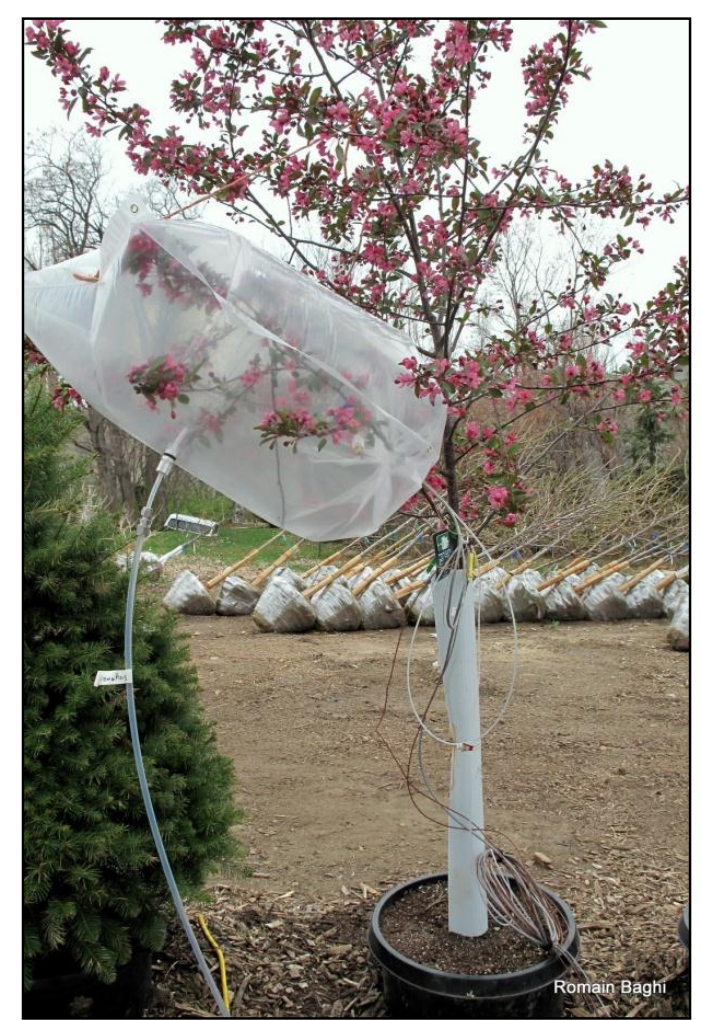

Fig. 1. Branch enclosure experiment setup on a crabapple tree during its flowering period.

\subsection{Biomass dry weight determination}

Dry biomass weight of the enclosed material is needed to normalize emission rates; however, cutting the branch for a weight estimate may stress the plant and induce an abnormal emission response. Therefore, instead of harvesting the enclosed branch, blossoms on the branches investigated were counted, and an equivalent number of flowers were harvested from another tree of the same species for flower dry weight estimation. After the experiment biomass dry weight determinations were made for both flowers and leaves of every tree studied, with leaves harvested from the sampled branches. Collected biomass was dried for $24 \mathrm{~h}$ in a $50{ }^{\circ} \mathrm{C}$ oven.

\subsection{Environmental monitoring}

The following environmental variables were monitored: ambient air temperature, air temperature inside the enclosure, leaf temperature of enclosed foliage, relative humidity inside the enclosure, photosynthetically-active radiation (PAR) (measured outside the enclosure next to the bag), and ozone concentration using the same equipment as described in Ortega et al. (2008). PAR was measured by one sensor mounted on a tripod outside of the enclosures and placed right next to the studied trees. One thermocouple was used to monitor 
ambient air temperature. A thermocouple was placed in each bag to monitor the temperature inside the enclosure. BVOC and particularly sesquiterpenes are very reactive. It was therefore important that oxidant levels inside the enclosure were kept low. Ozone concentrations in the enclosure were measured regularly, and were usually below 2 ppbv. Environmental data were acquired at $1 \mathrm{~s}$ and averaged and recorded every 5 min using a Campbell Scientific CR10X datalogger (Campbell Scientific, Logan, UT, USA).

\subsection{Normalized emission rate calculations}

Temperature dependencies for emissions of monoterpenes, benzenyl alcohol and benzyl aldehyde, oxygenated monoterpenes, and sesquiterpenes were observed in this study. There was no obvious light dependency in observed emissions. Normalized emission rates, referred to here as basal emission rates (BER), were calculated for conditions of $T_{\mathrm{S}}=30^{\circ} \mathrm{C}$ using the algorithm of Guenther et al. (1993); $E=\operatorname{BER}\left[\exp \left(\beta\left(T-T_{\mathrm{s}}\right)\right)\right]$, where $E$ is emission rate and $T$ is leaf temperature. $\beta$ was derived from experimental results for each tree. The results for the flower dry weight and leaf biomass determination were used to normalize emission rates to the amount of biomass inside the enclosure. Since leaves had just started to develop on the crabapple by the end of the flowering period, only flower petal dry weight was considered for normalizing emission rates. For the control experiments conducted after the flowering had subsided, the leaf biomass inside the enclosure was used to normalize emission rates.

\subsection{Modeling}

The Model of Emissions of Gases and Aerosols from Nature version 2.0 (MEGANv2.0) was applied for conditions in Boulder, Colorado, USA (latitude $40.0^{\circ} \mathrm{N}$, longitude $105.3^{\circ} \mathrm{W}$, elevation $1600 \mathrm{~m}$ ), which is located at the border of the Rocky Mountain and Central Plains ecoregions. Floral and foliar BVOC emissions were estimated using a single grid version of MEGAN (Guenther et al., 2006), which is driven by both land cover data and environmental conditions. Land cover inputs included the City of Boulder tree inventory and an urban tree cover fraction estimate. Tree cover was estimated by analyzing high resolution land surface imagery using the approach described by Duhl et al. (2011), whereby the Boulder area was divided into 900 cells (in this case, we selected a cell size of $10 \mathrm{~s}$ by $10 \mathrm{~s} ; \sim 0.73 \mathrm{~km}^{2}$ ). 350 cells located in residential, commercial/industrial, and city park land use classes within the city limits were randomly evaluated; average tree cover fraction was found to be 0.15 . Tree species information for Boulder was derived from a municipal tree resource analysis report by Boulder foresters (City of Boulder, 2005). Since there were no data available for the tree species composition on private property, for the purpose of this study it was assumed to be the same as on city property and BVOC emissions were assumed to be the same on public and private land throughout the city. Monoterpene emissions were calculated for April to June 2009. Temperature and solar radiation inputs for MEGAN were obtained from a University of Colorado weather station (http: //foehn.colorado.edu/weather/atoc1/). Observed floral emission rates were included in the model for honey locust and crabapple using the experimental results of this study, as together these two species represent $\sim 64 \%$ of the fraction of insect-pollinated flowering street trees in Boulder that produce conspicuous flowers, and $>13 \%$ of total street trees (by number) according to the tree inventory. Hawthorn and horse chestnut trees did not exhibit significantly different emissions during flowering as compared to non-flowering emissions and were therefore excluded from the simulations.

\section{Results and discussion}

Blooming occurred at different times for each tree species and lasted between 7 and 18 days. Figure 2 shows the flowering period (shaded) along with the sampling schedule for each species.

\subsection{Emission results}

BVOC emission rates varied significantly between vegetation species. Identified floral emissions showed a strong dependence on temperature and consequently were much higher during the day. The following section provides results for each of the species investigated.

\subsection{Crabapple}

Crabapple flowers appeared first, in late April, at a time when leaves were still in the bud stage. Benzyl alcohol and benzaldehyde were the only volatiles identified from branch enclosure samples. Figure 3 shows emission rate results for a typical day for each compound and Fig. 4 depicts the temperature dependence of both compounds.

The averaged contribution of benzyl alcohol and benzaldehyde to the overall emissions was $94 \%$ and $6 \%$, respectively. The averaged total normalized emission rate during the flowering period was $93 \mu \mathrm{gCg} \mathrm{g}^{-1} \mathrm{~h}^{-1}$ (standard deviation $\sigma$, determined by repeated experiments on the same branch, was $30 \mu \mathrm{gCg}^{-1} \mathrm{~h}^{-1}$ ). The emissions of both compounds exhibited clear temperature dependencies as presented in Fig. 4, which is similar to the dependencies observed for foliage terpenoid emissions. Emissions of both compounds dropped to near detection limits after the flowers had withered (Fig. 5). This finding shows that VOC emissions from crabapple are dominated by compounds released during the blooming stage. The emissions recorded from crabapple during the flowering period are among the highest BVOC emission rates reported from vegetation, i.e. these rates are on the same order as isoprene emission rates from 


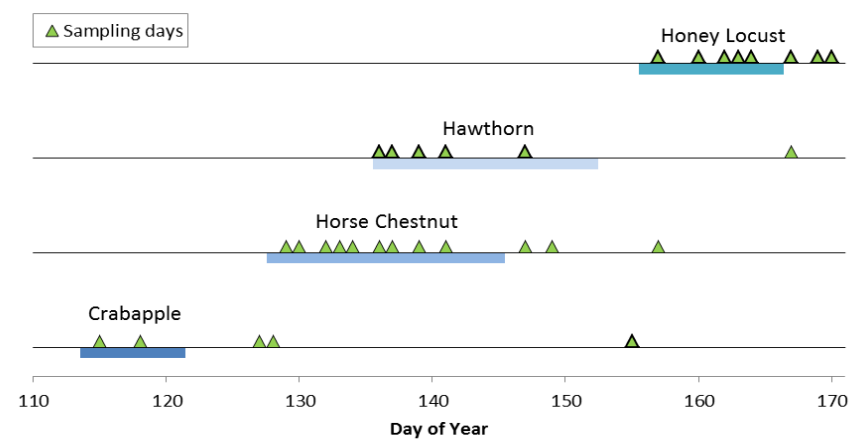

Fig. 2. Blooming periods (marked in blue) for crabapple, horse chestnut, hawthorn, and honey locust trees investigated in 2009. Sample collection days are shown by green triangles.

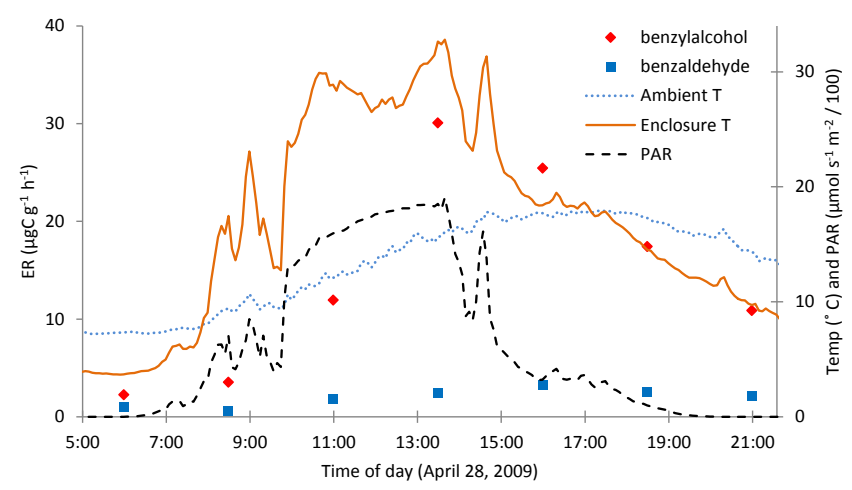

Fig. 3. Profile of benzyl alcohol and benzaldehyde emissions from crabapple for a day of measurements at full bloom with temperature inside the enclosure, ambient temperature and photosynthetically active radiation (PAR).

oak trees (Guenther et al., 1993; Sharkey et al., 1996; Geron et al., 2001). Benzenoids have been reported as abundant floral scent emissions in a number of other studies on floral volatiles (Dudareva et al., 1998; Pichersky and Gershenzon, 2000; Van Schie et al., 2006). The results shown here in particular agree with Loughrin et al. (1990), who also identified benzyl alcohol as well as benzaldehyde in apple flower emissions.

\subsection{Horse chestnut}

Compounds identified in the horse chestnut branch enclosure samples included thujene, $\alpha$ - and $\beta$-pinene, camphene, $\beta$-myrcene, $\alpha$ - and $\gamma$-terpinene, o-cymene, $\beta$-phellandrene, terpinolene, 4-terpineol, methyl salicylate, $\alpha$-terpineol, and limonene.

Figure S1 in the Supplement shows emission rate results for a typical day for the major compounds emitted. Normalized emission rates were calculated using an empirically-derived $\beta$-factor of 0.20 for the flowering period and 0.21 after flowering (Fig. 6). The average total basal
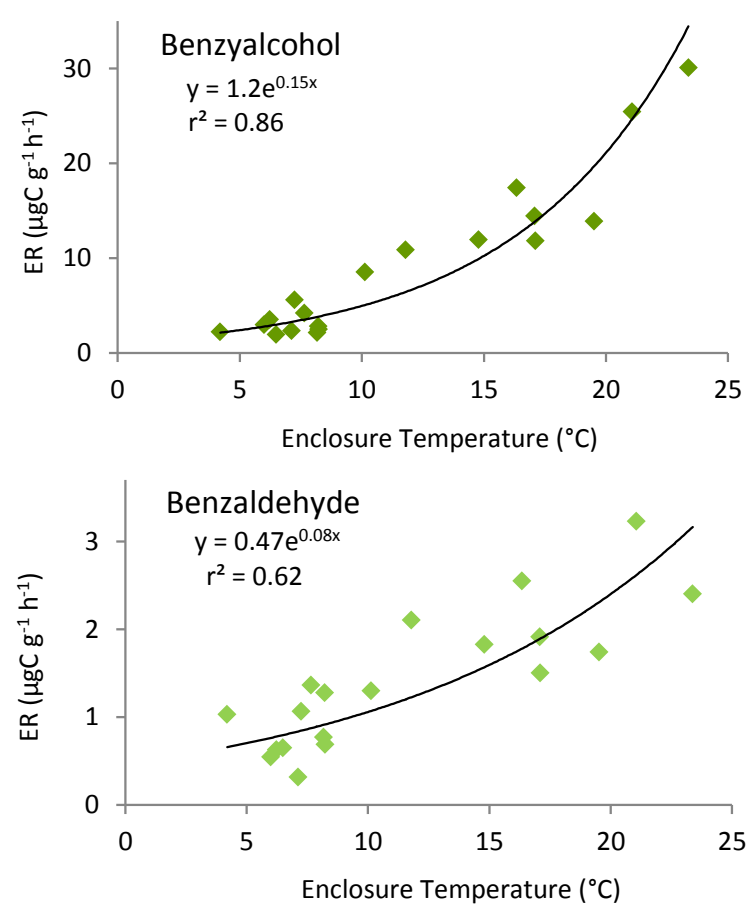

Fig. 4. Emission rates of benzyl alcohol and benzaldehyde during blooming as a function of air temperature inside the enclosure from a crabapple experiment.

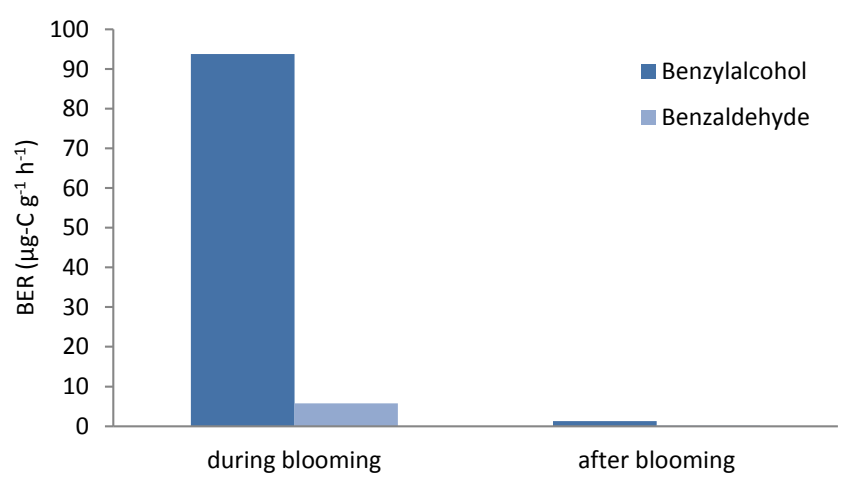

Fig. 5. Comparison of basal emission rates $\left(30^{\circ} \mathrm{C}\right)$ of benzylalcohol and benzaldehyde from crabapple before and after the flowering period.

BVOC emission rate during flowering was $9.1 \mu g \mathrm{gg}^{-1} \mathrm{~h}^{-1}$ $\left(\sigma=3.0 \mu \mathrm{gC} \mathrm{g} \mathrm{g}^{-1} \mathrm{~h}^{-1}\right)$, whereas after the flowering period emissions reached $12 \mu \mathrm{gCg} \mathrm{g}^{-1} \mathrm{~h}^{-1} \quad\left(\sigma=6.3 \mu \mathrm{gCg} \mathrm{g}^{-1} \mathrm{~h}^{-1}\right)$ (Fig. 7). $\alpha$-pinene, $\beta$-pinene, and limonene were the most abundant individual compounds emitted. The data in Figs. 6 and 7 show no significant change in the emission rates of these compounds during the blooming stage as compared to afterwards. However, the compounds terpinolene, 4-terpineol, methyl salicylate and $\alpha$-terpineol show postblooming increases. 

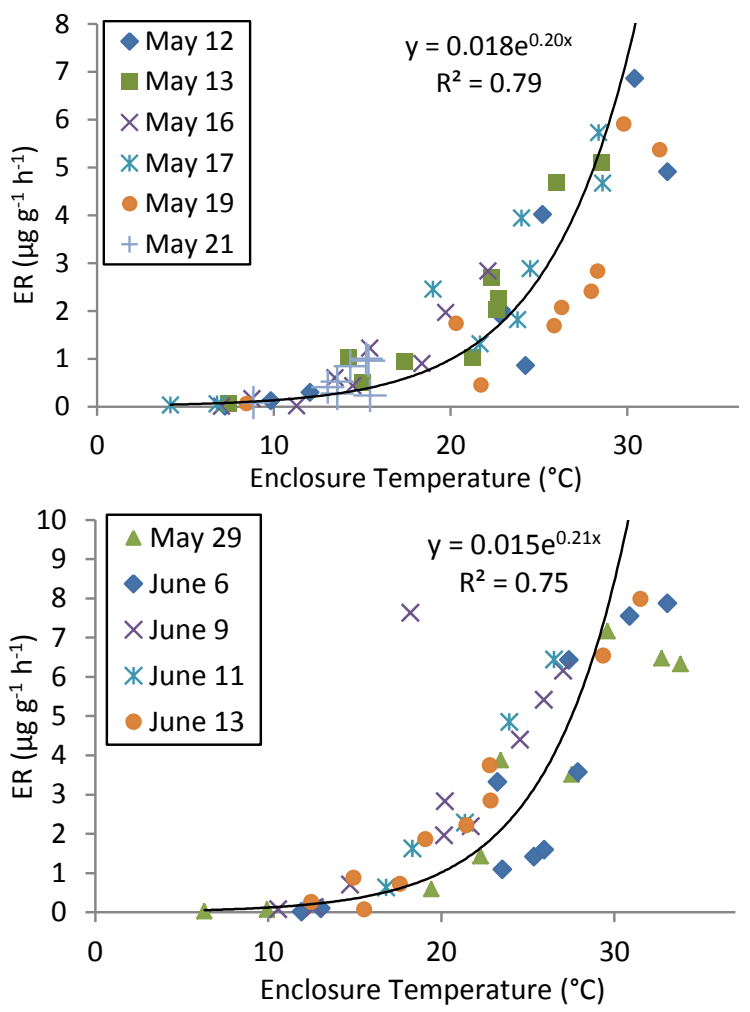

Fig. 6. Emission rates (expressed as the sum of monoterpenes) from horse chestnut as a function of temperature during blooming (left), and after the end of the blooming period (right).

\subsection{Honey locust}

Forty samples were collected during the flowering period of the honey locust tree and twenty more samples were taken after flowering. Monoterpenes and oxygenated monoterpenes were identified, including $\alpha$-thujene, $\alpha$ - and $\beta$-pinene, $\beta$-myrcene, o-cymene, $\beta$-phellandrene, limonene, $\gamma$-terpinene and $\alpha$-terpineol. The average normalized total MT emission rate during the flowering period was $5.3 \mu \mathrm{gCg}{ }^{-1} \mathrm{~h}^{-1}\left(\sigma=3.5 \mu \mathrm{gCg}^{-1} \mathrm{~h}^{-1}\right)$ with $\alpha$-pinene, $\beta$ pinene, and limonene being the dominant BVOC (Fig. 8). Figure S2 in the Supplement shows the temperature dependence of the emissions. After flowering, average emission rates dropped to $1.2 \mu \mathrm{gCg}^{-1} \mathrm{~h}^{-1}\left(\sigma=0.85 \mu \mathrm{gC} \mathrm{g}^{-1} \mathrm{~h}^{-1}\right)$ (Fig. 9); $\gamma$-terpinene, $\beta$-phellandrene, and limonene were the major BVOC emitted at this time.

\subsection{Hawthorn}

Two sesquiterpenes, $\beta$-caryophyllene and humulene were identified in the hawthorn emissions during flowering (Fig. S3, in the Supplement). Averaged BER for $\beta$-caryophyllene and humulene were $15.1 \mathrm{ngC} \mathrm{g}^{-1} \mathrm{~h}^{-1}$ $\left(\sigma=18 \mathrm{ngC} \mathrm{g}^{-1} \mathrm{~h}^{-1}\right) \quad$ and $\quad 4.4 \mathrm{ngC} \mathrm{g}^{-1} \mathrm{~h}^{-1} \quad(\sigma=$ $5.6 \mathrm{ngC} \mathrm{g}^{-1} \mathrm{~h}^{-1}$ ), respectively (Fig. S4, in the Supplement).

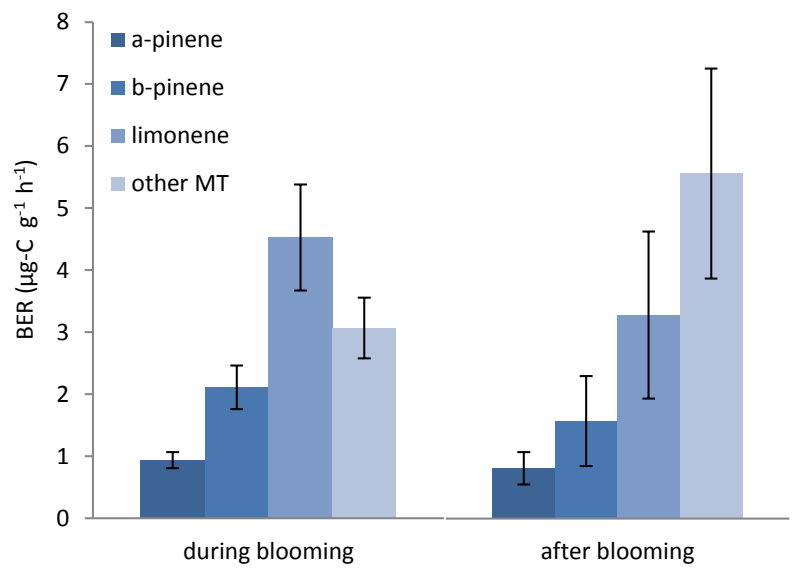

Fig. 7. Average normalized emission rates $\left(30^{\circ} \mathrm{C}\right)$ for $\alpha$-pinene, $\beta$ pinene, limonene, and other monoterpenes from horse chestnut during and after the blooming period. Error bars represent $95 \%$ confidence intervals from the averaging of individual results from four experiments.

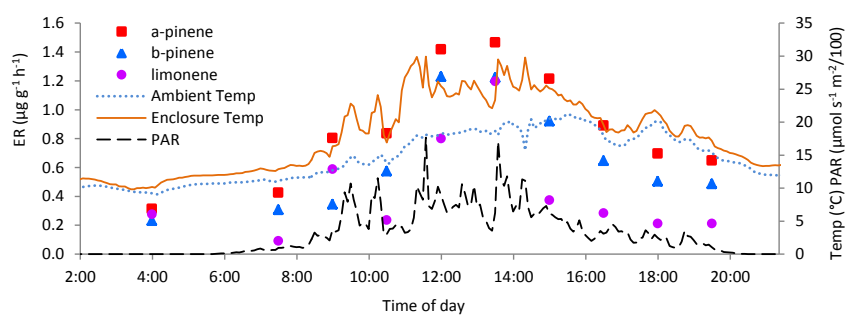

Fig. 8. Emission rates for $\alpha$-pinene, $\beta$-pinene, and limonene from a honey locust branch enclosure on 9 June with concurrently measured environmental parameters.

These compounds were also identified in the later foliage emissions. The post-flowering average emission rates were $4.0 \mathrm{ngC} \mathrm{g}^{-1} \mathrm{~h}^{-1}\left(\sigma=6.9 \mathrm{ngC} \mathrm{g}^{-1} \mathrm{~h}^{-1}\right)$ and $0.5 \mathrm{ngC} \mathrm{g}^{-1} \mathrm{~h}^{-1}$ $\left(\sigma=0.8 \mathrm{ngC} \mathrm{g}^{-1} \mathrm{~h}^{-1}\right)$ for caryophyllene and humulene, respectively. A third sesquiterpene, $\alpha$-farnesene, and the monoterpene limonene, neither of which were observed during flowering, were detected in the hawthorn emissions after flowering.

\subsection{Modeling results}

Figure 10 presents the results of the MEGAN model simulations performed for the 1 April-30 June 2009 simulation period. For the MT time series, emissions were calculated using default MEGAN species-specific MT emission rates for all tree species in the City of Boulder tree inventory. The floral time series incorporates BER as determined in the present study. Floral emissions can be substantial during periods of flowering. Overall, floral BVOC emissions are equivalent to $11 \%$ of MT emissions integrated over the three months simulation period. During the crabapple blooming period, emissions from flowers were as high as $116 \%$ of the estimated 


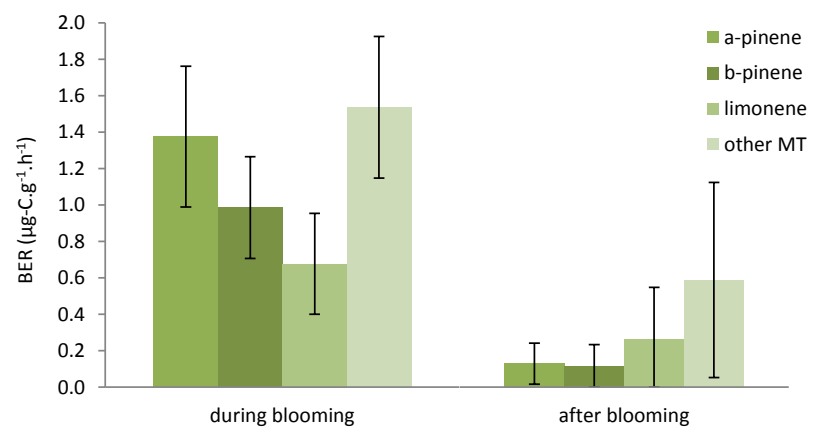

Fig. 9. Comparison of daily averaged and normalized emission rates $\left(30^{\circ} \mathrm{C}\right)$ for $\alpha$-pinene, $\beta$-pinene and limonene, and other monoterpenes from honey locust during and after the flowering period. Error bars represent 95 percent confidence intervals.

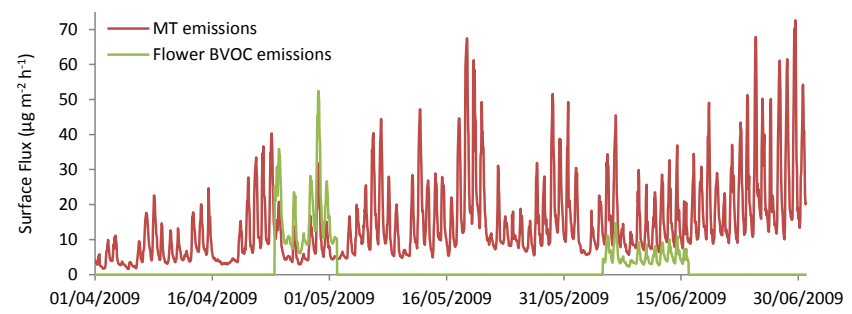

Fig. 10. Modeled sum of monoterpenes (MT) emitted from foliage (using default MEGAN emission rates; red trace) as well as modeled floral emissions of MT + other BVOC for the City of Boulder (green trace) based on the measurements conducted in the present study during spring 2009.

non-flower (foliage) MT emissions (Fig. 11). Honey locust flowers appear later in the season (Fig. 12); during that time these emissions represent $36 \%$ of MT emissions.

The simulated estimates have high associated uncertainties due to assumptions made, such as using the city-maintained tree inventory to represent tree species composition across the entire domain. It should also be recognized that the contribution of floral emissions to total biogenic emissions within other urban areas may be quite different from what was observed in Boulder. As a comparison, in the southern US city of Riverside, California, flowering trees represent $40 \%$ of total street trees with more than 10 different flowering tree species according to the City of Riverside urban tree inventory. It should also be noted that floral emissions within a city may be clustered in some regions, such as city parks and specific neighborhoods, and so could make a higher contribution in some areas and a lower contribution in others. Finally, we would like to emphasize that although in the present analysis a direct comparison of MT emissions from honey locust flowers against simulated leaf MT emissions is made, this is not the case for crabapple, in which the dominant BVOC emitted (benzyl alcohol and benzaldehyde) are oxygenated compounds. Species-specific emission factors for oxygenated compounds have a high de-

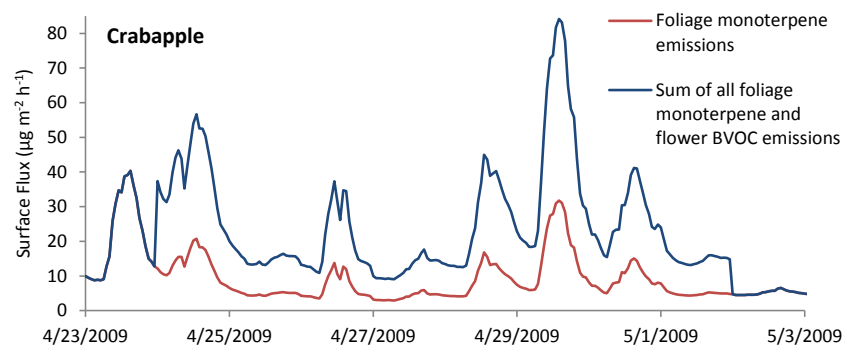

Fig. 11. Time series showing modeled total foliage and floral BVOC emissions (blue) and default MEGAN, foliage monoterpene emissions only (red), during the crabapple flowering period for the City of Boulder urban area.

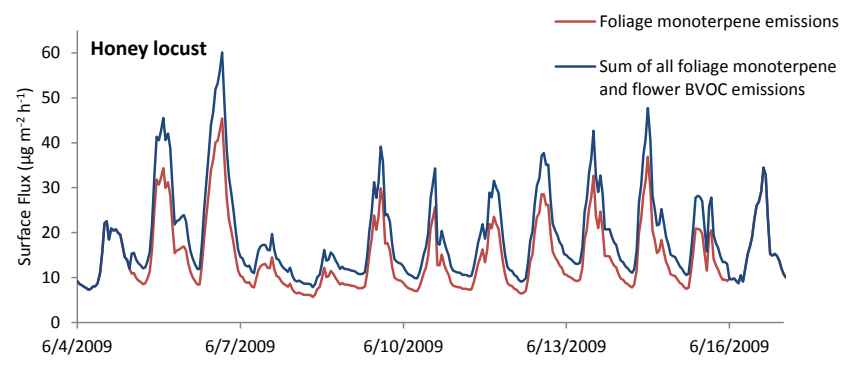

Fig. 12. Time series of modeled total floral and foliage BVOC emissions (blue) and default MEGAN, foliage monoterpene emissions only (red), during the honey locust flowering period for the City of Boulder urban area.

gree of uncertainty, and as such, we felt it prudent to instead compare our simulated floral emission estimates for these compounds with simulated MT emissions, which have substantially lower uncertainties associated with their emission factors.

\section{Conclusions}

This study represents an attempt to assess the significance of urban tree floral BVOC emissions at an urban scale. The findings demonstrate that floral BVOC emissions may constitute a significant seasonal source of BVOC in areas containing high proportions of flowering trees, with floral emissions approaching and possibly even exceeding nonisoprene BVOC emissions during the peak flowering period. These emissions estimates are based on the survey of $\sim 65 \%$ of the insect-pollinated flowering tree species present in the tree inventory and did not include catkin-producing species. Therefore, reported emissions should be considered lower-bounds of the likely actual emissions from urban trees within the study domain. These estimates suggest that floral tree emissions should be more closely examined and possibly considered in emissions models. To that end, efforts should be made to better understand whether municipal tree inventories are representative of the overall species 
composition in urban settings. Additional screening experiments of important flowering tree species should also be conducted and the temporal, species-specific blooming patterns of these trees should be characterized to better quantify the significance of floral emissions in locations which contain substantial fractions of flowering species. The timing of many phenological processes (such as bud-burst, flowering, etc.) may shift in response to global climatic changes. In addition to ecological repercussions associated with climatic shifts (such as chemically mediated biological interactions between plants and their pollinators or even herbivores), changes and shifts in floral BVOC emissions might occur. The potential also exists for the timing of these floral emissions bursts to coincide with the Northern Hemisphere springtime ozone maximum, a scenario with implications for urban air quality (due to the reactive nature of many BVOC chemical species); all of these possibilities highlight the need for further research in this area.

\section{Supplementary material related to this article is available online at: http://www.biogeosciences.net/9/ 3777/2012/bg-9-3777-2012-supplement.pdf.}

Acknowledgements. This research was supported by the National Science Foundation, project ATM-0608582. We thank the Creekside Nursery for accommodating the emissions experiment.

Edited by: N. Saigusa

\section{References}

Adams, R. P.: Identification of Essential Oils by Ion Trap Mass Spectrometry, Academic Press, San Diego, USA, 1989.

Andreae, M. O. and Crutzen, P. J.: Atmospheric aerosols: Biogeochemical sources and role in atmospheric chemistry, Science, 276, 1052-1058, 1997.

Arey, J., Corchnoy, S. B., and Atkinson, R.: Emission of linalool from Valencia orange blossoms and its observation in ambient air, Atmos. Environ., 25, 1377-1381, 1991.

Baraldi, R., Rapparini, F., Rossi, F., Latella, A., and Ciccioli, P.: Volatile organic compound emissions from flowers of the most occuring and economically important species of fruit trees, Phys. Chem. Earth, 24, 729-732, 1999.

Ciccioli, P., Brancaleoni, E., Frattoni, M., Di Palo, V., Valentini, R., Tirone, G., Seufert, G., Bertin, N., Hansen, U., Csiky, O., Lenz, R., and Sharma, M.: Emission of reactive terpene compounds from orange orchards and their removal by within-canopy processes, J. Geophys. Res., 104, 8077-8094, 1999.

City of Boulder, Colorado, Municipal Tree Resource Analysis, available at:www.bouldercolorado.gov, 2005.

Dudareva, N., Raguso, R. A., Wang, J., Ross, J. R., and Pichersky, E.: Floral Scent Production in Clarkia breweri, Plant Physiol., 116, 599-604, 1998.

Duhl, T., Guenther, A., and Helmig, D.: Estimating urban vegetation cover fraction using Google Earth ${ }^{\circledR}$ Images, J. Land Use Science, 1-19, doi:10.1080/1747423X.2011.587207, 2011.
Fuentes, J. D., Lerdau, M., Atkinson, R., Baldocchi, D., Bottenheim, J. W., Ciccioli, P. Lamb, B., Geron, C., Gu, L., Guenther, A., Sharkey, T. D., and Stockwell, W.: Biogenic hydrocarbons in the atmospheric boundary layer: A review, B. Am. Meteorol. Soc., 81, 1537-1575, 2000.

Geron, C., Harley, P., and Guenther, A.: Isoprene emission capacity for US tree species, Atmos. Environ., 35, 3341-3352, 2001.

Guenther, A. B., Zimmerman, P. R., Harley, P. C., Monson, R. K., and Fall, R.: Isoprene and Monoterpene Emission Rate Variability: Model Evaluations and Sensitivity Analyses, J. Geophys. Res., 98, 12609-12617, 1993.

Guenther, A., Karl, T., Harley, P., Wiedinmyer, C., Palmer, P. I., and Geron, C.: Estimates of global terrestrial isoprene emissions using MEGAN (Model of Emissions of Gases and Aerosols from Nature), Atmos. Chem. Phys., 6, 3181-3210, doi:10.5194/acp-63181-2006, 2006.

Helmig, D., Revermann, T., Pollmann, J., Kaltschmidt, O., Jiménez Hernández, A., Bocquet, F., and David, D.: Calibration system and analytical considerations for quantitative sesquiterpene measurements in air, J. Chromatogr. A, 1002, 193-211, 2003.

Helmig, D., Bocquet, F., Pollmann, J., and Revermann, T.: Analytical techniques for sesquiterpene emission rate studies in vegetation enclosure experiments, Atmos. Environ., 38, 557-572, 2004a.

Helmig, D., Revermann, T., and Hall, B.: Characterization of a pressurized $\mathrm{C}_{5}-\mathrm{C}_{16}$ hydrocarbon gas calibration standard for air analysis, Anal. Chem., 76, 6528-6534, 2004b.

Helmig, D., Ortega, J., Guenther, A., Herrick, J., and Geron, C.: Sesquiterpene emissions from Loblolly Pine and their potential contribution to biogenic aerosol formation in the Southeastern US, Atmos. Environ., 40, 4150-4157, 2006.

Ibrahim, M. A., Egigu, M. C., Kasurinen, A., Yahya, A., and Holopainen, J. K.: Diversity of volatile organic compound emissions from flowering and vegetative branches of Yeheb, Cordeauxia edulis (Caesalpiniaceae), a threatened evergreen desert shrub, Flavour Frag. J., 25, 83-92, 2010.

Johne, A. B., Weissbecker, B., and Schütz, S.: Volatile Emissions from Aesculus hippocastanum Induced by Mining of Larval Stages of Cameraria ohridella Influence Oviposition by Conspecific Females, J. Chem. Ecol., 32, 2303-2319, 2006.

Knudsen, J. T., Eriksson, R., Gershenzon, J., and Ståhl, B.: Diversity and Distribution of Floral Scent, Bot. Rev., 72, 1-120, 2006.

Li, Z.-G., Lee, M.-R., and Shen, D.-L.: Analysis of volatile compounds emitted from fresh Syringa oblata flowers in different florescence by headspace solid-phase microextraction-gas chromatography-mass spectrometry, Anal. Chim. Acta, 576, 4349, 2006.

Loughrin, J. N., Hamilton-Kemp, T. R., Andersen, R. A., and Hildebrand, D. F.: Volatiles from flowers of Nicotiana sylvestris, N. otophora and Malus $\times$ domestica: headspace components and day/night changes in their relative concentrations, Phytochemistry, 29, 2473-2477, 1990.

Martin, D. M., Touba, O., Chiang, A., Lo, B. C., Ohse, S., Lundb, S. T., and Bohlmann, J.: The bouquet of grapevine (Vitis vinifera L. cv. Cabernet Sauvignon) flowers arises from the biosynthesis of sesquiterpene volatiles in pollen grains, P. Natl. Acad. Sci., 106, 7245-7250, 2009.

McTavish, H. S., Davies, N. W., and Menary, R. C.: Emission of Volatiles From Brown Boronia Flowers: Some Comparative 
Observations, Ann. Bot.-London, 86, 347-354, 2000.

Mena Granero, A., Egea Gonzalez, F. J., Guerra Sanz, J. M., and Martínez Vidal, J. L.: Analysis of Biogenic Volatile Organic Compounds in Zucchini Flowers: Identification of Scent Sources, J. Chem. Ecol., 31, 2309-2322, 2005.

Müller, K., Pelzing, M., Gnauk, T., Kappe, A., Teichmann, U., Spindler, G., Haferkorn, S., Jahn, Y., and Herrmann, H.: Monoterpene emissions and carbonyl compound air concentrations during the blooming period of rape (Brassica napus), Chemosphere, 49, 1247-1256, 2002.

Ortega, J. and Helmig, D.: Approaches for quantifying reactive and low-volatility biogenic organic compound emissions by vegetation enclosure techniques - Part A, Chemosphere 72, 343-364, 2008.

Ortega, J., Helmig, D., Daly, R. W., Tanner, D. M., Guenther, A. B., and Herrick, J. D.: Approaches for quantifying reactive and low-volatility biogenic organic compound emissions by vegetation enclosure techniques - Part B: Applications, Chemosphere, 72, 365-380, 2008.

Pichersky, E. and Gershenzon, J.: The formation and function of plant volatiles: perfumes for pollinator attraction and defense, Curr. Opin. Plant Biol., 5, 237-243, 2002.

Rapparini, F., Baraldi, R., and Facini, O.: Seasonal variation of monoterpene emission from Malus domestica and Prunus avium, Phytochemistry, 57, 681-687, 2001.
Robertson, G. W., Griffiths, D. W., Woodford, J. A. T., Birch, A. N. E., Picket, J. A., and Wadhams, L. J.: A comparison of the flower volatiles from hawthorn and four raspberry cultivars, Phytochemistry, 33, 1047-1053, 1993.

Rodriguez-Saona, C., Parra, L., Quiroz, A., and Isaacs, R.: Variation in highbush blueberry floral volatile profiles as a function of pollination status, cultivar, time of day and flower part: implications for flower visitation by bees, Ann. Bot., 107, 1377-1390, doi:10.1093/aob/mcr077, 2011.

Sharkey, T. D., Singsaas, E. L., Vanderveer, P. J., and Geron, C.: Field measurements of isoprene emission from trees in response to temperature and light, Tree Physiol., 16, 649-654, 1996.

Tarvainen, V., Hakola, H., Hellén, H., Bäck, J., Hari, P., and Kulmala, M.: Temperature and light dependence of the VOC emissions of Scots pine, Atmos. Chem. Phys., 5, 989-998, doi:10.5194/acp-5-989-2005, 2005.

Van Schie, C. C., Haring, M. A., and Schuurink, R. C.: Regulation of terpenoid and benzenoid production in flowers, Curr. Opin Plant Biol., 9, 203-208, 2006.

Yamaguchi, K. and Shibamoto, T.: Volatile constituents of the chestnut flower, J. Agric. Food Chem., 28, 82-84, 1980.

Zhuang, X., Klingeman, W. E., Hu, J., and Chen, F.: Emission of volatile chemicals from flowering dogwood (Cornus florida L.) flowers, J. Agric. Food Chem., 56, 9570-9574, 2008. 